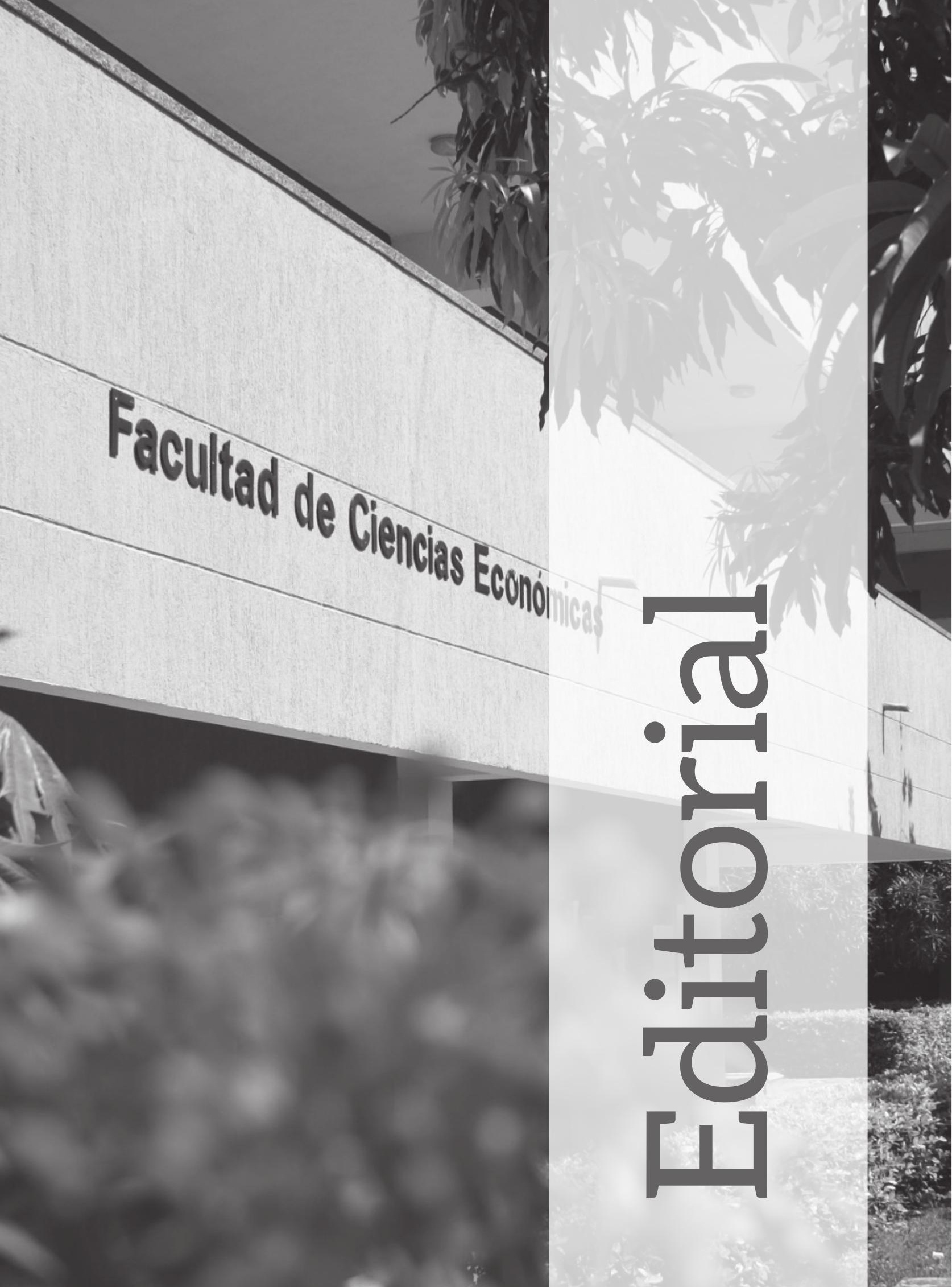





\title{
Impacto Científico en el Departamento de Bolívar (Colombia)
}

\author{
Andrés Escobar-Espinoza* \\ Colombia \\ Nicolás López-Verhelst** \\ Colombia
}

Uno de los principales retos de las publicaciones científicas es la importancia que estas tienen en el mundo científico. Lo anterior se basa en los diferentes indicadores bibliometricos que se han desarrollado para evaluar el impacto científico de las publicaciones (Hirsch, 2005; Garfield, 2006; Escobar \& López, 2017). En éste sentido, es importante analizar el impacto científico de las publicaciones seriadas que se editan en el Departamento de Bolívar (Colombia), independiente del área del conocimiento, con el fin de conocer algunos indicadores bibliometricos en la región norte de Colombia. Lo anterior permite evidenciar si existen avances en el tema y si estos son homogéneos o heterogéneos. Lo anterior es importante teniendo en consideración que el Departamento de Bolívar pertenece a una región con importantes rezagos en diferentes indicadores cuando se contrasta con las principales regiones o ciudades de Colombia.

En este sentido, se identificaron las revistas científicas editadas por distintas entidades públicas o privadas, entre las cuales se tienen: Saber, Ciencia \& Libertad, Panorama Económico, Aglala, Economía \& Región, Palobra, Cuadernos de Literatura del Caribe e Hispanoamérica, Ciencia y Salud Virtual, Revista Internacional de Cooperación y Desarrollo. Las anteriores representan las principales publicaciones seriadas editadas en el Departamento de Bolívar, que cumplen con los principales criterios de gestión editorial y periodicidad.

A continuación se presentan los principales indicadores bibliométricos de las mencionadas revistas, a partir de la información disponible en Google Scholar mediante Publish or Perish (Harzing, 2007):

\footnotetext{
* Editor-Revista Panorama Económico de la Universidad de Cartagena. Correo de contacto: aescobare@unicartagena.edu.co

** Asistente Editorial - Revista Panorama Económico de la Universidad de Cartagena. Correo de contacto: nlopez@unicartagena.edu.co
} 
Tabla 1: Indicadores bibliometricos de revistas científicas, 2012-2016

\begin{tabular}{|c|c|c|c|c|c|}
\hline REVISTA & INSTITUCIÓN & $\begin{array}{l}\text { GRAN ÁREA DEL } \\
\text { CONOCIMIENTO }\end{array}$ & $\begin{array}{l}\text { ÍNDICE } \\
\text { H5 }\end{array}$ & $\begin{array}{l}\text { NÚMERO } \\
\text { DE CITAS }\end{array}$ & PERIODICIDAD \\
\hline Aglala & $\begin{array}{l}\text { Corp. Univ. } \\
\text { Rafael Núñez }\end{array}$ & $\begin{array}{l}\text { Ciencias } \\
\text { Sociales }\end{array}$ & 8 & 101 & Anual \\
\hline $\begin{array}{l}\text { Cuadernos de } \\
\text { Literatura del Caribe } \\
\text { e Hispanoamérica }\end{array}$ & $\begin{array}{l}\text { Universidad } \\
\text { de Cartagena } \\
\text { Universidad del } \\
\text { Atlántico }\end{array}$ & Humanidades & 7 & 104 & Anual \\
\hline $\begin{array}{c}\text { Ciencia y Salud } \\
\text { Virtual }\end{array}$ & $\begin{array}{l}\text { Corp. Univ. } \\
\text { Rafael Núñez }\end{array}$ & $\begin{array}{l}\text { Ciencias } \\
\text { de la Salud }\end{array}$ & 4 & 90 & Semestral \\
\hline Economía \& Región & $\begin{array}{l}\text { Universidad } \\
\text { Tecnológica } \\
\text { de Bolívar }\end{array}$ & $\begin{array}{l}\text { Ciencias } \\
\text { Sociales }\end{array}$ & 5 & 142 & Semestral \\
\hline Palobra & $\begin{array}{l}\text { Universidad } \\
\text { de Cartagena }\end{array}$ & $\begin{array}{l}\text { Ciencias } \\
\text { Sociales }\end{array}$ & 4 & 47 & Anual \\
\hline $\begin{array}{l}\text { Panorama } \\
\text { Económico }\end{array}$ & $\begin{array}{l}\text { Universidad } \\
\text { de Cartagena }\end{array}$ & $\begin{array}{l}\text { Ciencias } \\
\text { Sociales }\end{array}$ & 7 & 129 & Anual \\
\hline $\begin{array}{c}\text { Revista } \\
\text { Internacional de } \\
\text { Cooperación y } \\
\text { Desarrollo }\end{array}$ & $\begin{array}{c}\text { Universidad San } \\
\text { Buenaventura }\end{array}$ & $\begin{array}{l}\text { Ciencias } \\
\text { Sociales }\end{array}$ & 5 & 98 & Semestral \\
\hline $\begin{array}{l}\text { Saber, Ciencia } \\
\text { \& Libertad }\end{array}$ & $\begin{array}{l}\text { Universidad Libre } \\
\text { de Colombia }\end{array}$ & $\begin{array}{l}\text { Ciencias } \\
\text { Sociales }\end{array}$ & 6 & 121 & Semestral \\
\hline \multicolumn{3}{|c|}{ MÁXIMO } & 8 & 142 & \\
\hline \multicolumn{3}{|c|}{ MÍNIMO } & 4 & 47 & \\
\hline \multicolumn{3}{|c|}{ PROMEDIO } & 6 & 104 & \\
\hline
\end{tabular}

Es evidente que a pesar de ser una región con innumerables desafíos, se muestra que la gestión editorial ha permitido contar con revistas indexadas en el IBN Publindex, evidenciándose el fortalecimiento de los equipos editoriales. Por otro lado, los resultados en términos de impacto científico son alentadores, todas vez que según Colciencias, el valor mínimo del Índice de Hirsch para el periodo 2012-2016 es de dos (2). En promedio las publicaciones cuentan con un índice $\mathrm{H} 5$ de 6, por encima de los mínimos requeridos por Colciencias. Estos resultados son prometedores, dado que el Departamento de Bolívar es una de las regiones con menor cantidad de revistas científicas indexadas a nivel nacional. De esta manera se podría iniciar a reducir de alguna manera las brechas existentes con las principales regiones del país. 


\section{REFERENCIAS BIBLIOGRÁFICAS}

Escobar, A., \& Lopez, N. (2016). Visibilidad internacional de la Revista Panorama Economico. Panorama Economico, 24, 7-9.

Garfield, E. (2006). The History and Meaning of the Journal Impact Factor. JAMA, 295(1), 90-93.

Harzing, A. W. (2007). Publish or Perish. Obtenido de https://harzing.com/resources/ publish-or-perish.

Hirsch, J. E. (2005). An index to quantify an individual's scientific reserch output. Proceedings of the National Academy of Sciences PNAS, 102(46), 16569-16572. 


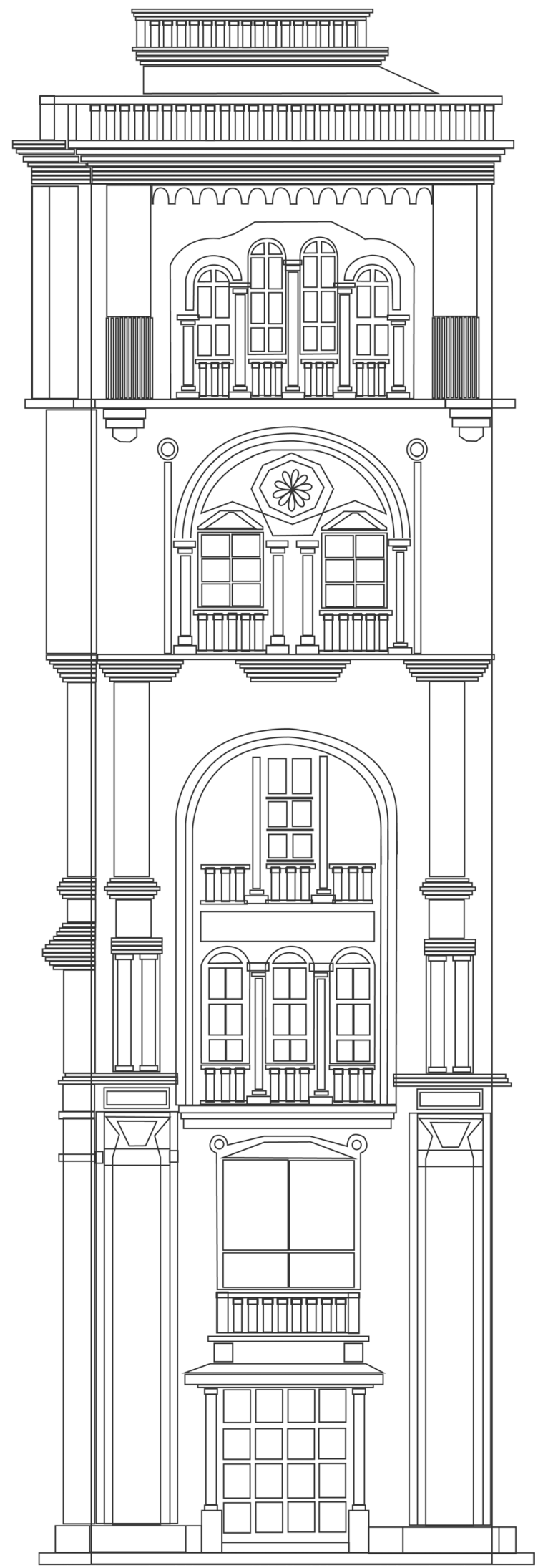

